\title{
Human Capital Development - The Key to Success for Albanian Companies
}

\author{
Msc. Alma Varfi (Phd Candidate) \\ Vodafone Albania, Human Resources Director \\ alma.varfi@vodafone.com \\ Dr. Arbi Agalliu \\ European University of Tirana, Faculty of Economy and Information Technology \\ arbi.agalliu@uet.edu.al
}

\section{Doi:10.5901/ajis.2014.v3n6p101}

\section{Abstract}

Economic development is linked intrinsically with the positive progress of economic entities. Human resources are widely recognized as the totality of employees in an organization, who are responsible for the latter's performance and further growth. Business operation is entrusted to employees, despite the results the company may have depending on employees' skills and competencies. Therefore, there exists a strong positive link between business development and human capital development. Based on the role employees have, and consequently on the need for them to be valuable and productive, lots of effort should be put from the companies since the beginning in finding the best recruitment methods, followed by the best performance measurement policies, development, motivation and integration of employees, so that the company may benefit from their best performance. Aiming to adapt this topic to the reality where we live, this paper includes specific examples on how companies operating in our country treat their "Human Capital". These examples are accompanied by valuable recommendations based mainly on international literature, so as to better orientate enterpreneurs towards contemporary policies of human resources management.

Keywords: Human capital, economic unit, productivity.

\section{Introduction}

In today's world, thre is a variety of types of businesses, in the product or service they offer, in their way of operation, their type of partnerships and ways of financing. Nevertheless, they all have a common goal - success - , despite the mission, goals or culture each one of them has. What we have learnt so far, based on the experience of the founders of the most successful organizations, or those which have resisted to market challenges for decades, is that they always had to believe in other individuals. Although ideas may be individual, even when financial opportunities may be very good, in order to make the business work, move forward, expand its activity and increase potential profits, there must be a great and skilled work forcewho will work in specific roles and perform well.

At this point it is important to note the mutual relationship between dhe employeer and its employees. This in fact is the most delicate and key factor which will affect business performance. The challenge lies in selecting the right employees and adjust them in the right position, a process not easy to realize. Employees of an organization are those who represent it, those who through knowledge, skills, day by day experience, dedication, will and tasks, achieve to drive the organization towards success. At the same time, the employees of an organization may be responsible also for the failure or bankruptcy of the latter.

The concept "human capital' was born out of the importance of having valuable and productive employees, as a necessity to achieve the objectives of a business. This concept implies "...quantity of competence, knowledge, personal and social attribute, including creativity, all these embodied in the ability to perform and produce economic value"(M. Simkovic, 2012).

Another definition of human capital is the following: "With human capital we mean the employees of an organization who have judgment experience, intelligence, ability to build relationships and address issues"( $R$. A. Noe; J. R. Hollenbeck; B. Gerhart; P. M. Wright; 2011, fq. 3).

Given that the core of this study consists in studying human capital and its importance as a success factor of the economic units, we deemed necessary the analysis of empirical results of this topic in terms of our country. The 
conclusions reached are such that can be attributed to both aforementioned parties, as we believe it is crucial to include each link in order to form the whole.

\section{Overview of Albanian Economy}

Below we present a general analysis of the current economic situation in Albania, in order to connect it afterwards with the human capital operating in Albanian companies.

First, we will present some key macroeconomic indicators over the years, to understand the economic progress in our country to date, as well as a possible prediction of its trend in the future.

The indicators considered are gross domestic product (GDP), unemployment and inflation.

Table 1. Data on GDP and inflation

\begin{tabular}{|c|c|c|c|}
\hline Year & GDP (with current prices, in million Lekë) & Gross Domestic Product (in \%) & Inflation (in \%) \\
\hline 2007 & 967,670 & 6.0 & 3.1 \\
\hline 2008 & $1,089,293$ & 7.5 & 2.2 \\
\hline 2009 & $1,148,082$ & 3.3 & 3.7 \\
\hline 2010 & $1,222,462$ & 3.8 & 3.4 \\
\hline 2011 & $1,282,255$ & 3.0 & 3.5 \\
\hline 2012 & NA & 1.3 & 2.0 \\
\hline 2013 & NA & 0.4 & 1.9 \\
\hline $2014^{*}$ & NA & 2.1 & 2.0 \\
\hline
\end{tabular}

* These are data resulted in the framework of forecasting

Source: Instat, Ministry of Finance,IMF assessments, Bank of Albania; (adjusted by authors)

Based on the data presented in the annual report of the Bank of Albania for the year 2013, we conclude that the Albanian economy was characterized by a relatively weak economic growth; specifically, this year marked the lowest economic growth in the country for the period studied (2007-2014). Such a situation is defined as a consequence of high uncertainties under the influence of an unstable global economic environment, more difficult financing conditions in the loans sector, as well as the weak aggregate demand.

This increase appears to be $0.4 \%$ in real terms. Such a condition, seen more specifically in the effects on business performance and labour market in Albania, has resulted in "...a slight increase in employment and salaries,... but also financial trouble for enterprises..." Bank of Albania, 2013, pg.19).

With regard to inflation - another important indicator for assessing a country's macroeconomic performance -, we can say that its fluctuation over the years has been within the target (2\%-4\%), determined by the Bank of Albania as the only legitimate authority of control on monetary policy in the country.

During 2012, inflation has fluctuated lightly, but still within the defined limits, "...thus reflecting the facilitating cycles of monetary policies' (Bank of Albania, 2012, pg 31); while the same indicator for 2013 was found to be 1.9\%, trying to go out of the lower limit of the range, which rises the concern about the sustainability and further development of the economy.

Another important macroeconomic element, such as unemployment, has shown fluctuations during 2013. At the end of the second quarter of 2012 and throughout 2013, the registered unemployement rate has resulted in 12.8\%, marking a decline of 0.2 percentage points in annual terms.

Based on the data of the "Report on Macroeconomic Developments" published by the Bank of Albania during the first half of 2013 , the total number of employees increased by $1.5 \%$ yoy.

There is also a slight improvement in the non-agricultural private sector where the number of employees has increased by $7.6 \%$ on an annual basis. According to the analysis of this report, expectations for employment in the following period are more optimistic for the industy sector, they continue to be positive for the service sector and are slightly more positive for the building sector. The below table includes two of the labour market indicators in Albania during the years $2008-2013$. 
Table 2. Labour market indicators in Albania

\begin{tabular}{|l|c|c|c|c|c|c|}
\hline \multicolumn{7}{|c|}{ Labour market } \\
\hline Year & 2008 & 2009 & 2010 & 2011 & 2012 & 2013 \\
\hline Number of employees (in thousands) & 974.1 & 899.3 & 916.9 & 928.0 & 955.0 & 966.0 \\
\hline Unemployment rate & 12.7 & 13.7 & 13.5 & 13.3 & 13.0 & 12.8 \\
\hline
\end{tabular}

Source: Bank of Albnaia, Annual Report 2013, pg 24(adjustment by the authors)

From the above table it is noticed that for the period presented above, the unemployment rate has had thehighest increase during 2007 (13.7\%), whereas in the following years there has been a continuous decline, reaching the level of $12.8 \%$ in 2013.

\section{Human Capital as a Key Factor to the Development of Companies}

Human capital is an integral part of any organization or institution. Edwin A. Locke in his book "Principles of Organizational Behaviour" states that: "Human capital is one of the biggest assets available to an organization which invests generously for this capital." (2003, pg. 43).

Considering the role played by the human resources in a company, various researchers have tried through scientific studies to understand, improve and motivate further the needs and performance of the employees, because these "...researchers consider human capital as an asset of the unit (organization; an asset which includes skills, experience and the necessary capacity to perform a given or undertaken task. On the other hand, there are individuals who view human capital as a mechanical means to the organization and not as a capital, which contributes significantly to the success or failure of the economic unit".Agalliu, 2013, pg 43).

An issue arises here which needs to be brought to attention and on which discussions are valuable. Let's focus more on the approach of this concept by the Albanian entrepreneurs.

Our country faces a new system of development and understanding of how the free market functions and its characteristics, compared to other more developed countries which have been at the forefront of these developments.

One of the components we see applied in the developed countries, and which unfortunately has not been formalized in its complete form in our country, is the concept and importance of the human resources.

As stated above, there are individuals who perceive their employees as "machines" programmed to perform a specific function, without taking into consideration any strategies, criteria and obligations that must be met from the phase of selecting the employees in a particular organization, to the policies of assessing their performance and motivation during their employment. Sometimes we hear that there are still employees of different categories who are truly inexistent, as they are not registered as such, therefore, they have no legally recognized rightsfor a salary, social or health insurance, not to mention other rights.

Although there is evidence which shows that such phenomena are fought every day, the fact remains that they still exist and the question is what to expect from the performance of employees frustrated by their employers? Maybe Albanian entrepreneurs have not yet realized that they cannot achieve what they want through such abuse facilitated by a nonexistent state which should normally be legally and economically powerful.

Nevertheless, one of the objectives of this paper is to raise the awareness of Albanian companies on the importance they should place on their employees, because, as Dean R. Spitzer states in his book about "Performance Measurement", "one of the most valuable assets is intellectual capital, which is divided in three categories: organization capital (patents, copyrights, trademark, infrastructure, culture), capital linked to the relationship between parties (the relationship with customers, offers, partners, competitors, government, community) and human capital (skills, knowledge and employees attitudes, talents)."(2007, pg. 220).

From this point of view, the issue takes a broader scope, given that companies, in order to create a good team of professional employees, should strive to create a structure dedicated to recruitment policies for their employees, training, performance evaluation, motivation, as well as the creation of a suitable working environment which encourages employees to do their best.

Therefore, Human Resources Management is responsible for the design and effective implementation of various policies, procedures and programs, the development of knowledge, skills, creativity, talent and use them optimally.

Based on the research and experience of the Irish training and consulting company "Optimum Resul", in materials 
about Human Resource Exellence, the key points that the Human Resources Management Department should keep in mind are:

\subsection{Recruitment and training}

This is the most important part of the human resources team. Human Resources managers should build plans and strategies to hire the right person, by defining the right criteria in line with the specific role. A crucial part of their duty is to also make employees aware of their objectives and obligations, as defined by the role.

On the other hand, when necessary, they should offer trainings to the employees based on organization needs. Thus, employees acquire new skills and have the opportunity to undertake new roles in the organization.

\subsection{Performance Evaluation}

Human Resources Management should encourage people who work in an organization to show their potential and provide them with suggestions on how to achieve their best.

Through individual discussions between human resources managers and employees, the former collect all the necesary information about the performance of the latter and thereafter define roles. Performance evaluation implemented on the basis of certain rules motivates employees.

\subsection{Motivating work atmosphere}

This factor is of utmost importance as employee performance is closely linked to the physical and cultural work environment. Good working conditions are the minimum employees require from employers. A clean, safe and healthy environment motivates employees to do their best. A friendly atmosphere offers colleagues work satisfaction.

\subsection{Conflict management}

In an organization there may be many issues which can cause conflicts between employees and employers, or between employees. Sometimes conflicts are inevitable, hence at this point, Human Resources Management members play the mediator role in order to solve conflicts in the right way. Moreover, they take measures to avoid the repetition of such conflicts in the future.

\subsection{Public Relations development}

It is the responsibility of Human Resources Management to establish good relations between employees and third parties. The former organize business meetings, seminars and other official meetings on behalf of the company, aiming to establish relations with other business sections.

\section{Study Case - Albanian Companies}

Aiming to approach as much as possible the reality in which Albanian companies operate, as well as the policies they apply for the capital available to them, we have refered to companies such as Infosoft Group, AMC and Vodafone Albania,widely known in the country for their activity. Speaking about its sucess in the recent years, "Infosoft Group" states that: "Recruitment and efficient management of Human Resources are the key elements in the success of every businesss. The progress and continuous growth of the 9 operating companies of InfoSoft Group are based on the talent and hard work of a staff selected with high professionalism. This is why in our point of view, human capital has been and will remain the most valuable asset. For us it is crucial that every person is well oriented towards a role for which he/she is more suitable."

As shown in the analysis of the above declaration, we should focus attention on the first phase of contact with the potential employee, the recruitment phase. If we refer to Susan Heathfield, Human Resources expert, she is right in saying that "finding the best possible people who can adapt to the culture and contribution of an organization is both a challenge and an opportunity."

Following this logic, the same author provides recommendations on how companies can improve their candidates 
list in the recruitment phase. "Companies which select their new employees from the candidates who present at their offices, or those who have applied online completing a form, are losing their best candidates. They (the best candidates) are working for someone else and maybe are not looking for a new job."(Heathfield, M, S. Pg1)

It is interesting to see the problem in this point of view, which makes us doubt and turn down the whole traditional way of recruiting employees as we know it and which is widely implemented in Albania. To provide examples on this phenomenon, we gathered data from mobile companies operating in our country and did not hesitate to share with us a serious problem such as the lack of potential candidates suitable to fill the vacancies in the company.

Below are the specific data for the above phenomenon:

Table 3. Data on the results of applications for vacancies at mobile operators

\begin{tabular}{|c|c|c|c|c|}
\hline Year & Vacancy & Number of vacancies & Number of appications & Non-successful applications (in\%) \\
\hline 2012 & Tax Analyst & 1 & 23 & 70 \\
\hline 2013 & Financial Analyst & 4 & 80 & 60 \\
\hline 2013 & IT developer & 8 & 140 & 80 \\
\hline 2013 & Marketing & 12 & 1230 & 90 \\
\hline
\end{tabular}

Source: Vodafone Albania (adjustment made by authors)

Facing such concerning data incites one to try to find out where the problem lies. Maybe the vacant roles are such that are not offered in our country? Maybe our universities have been unable to offer specific branches related to these positions? Or maybe our work force is not qualified enough to be part of the labour market?

These vacancies are part of Finance, management, IT, branches which are widely spread in our country. We also understand that such positions require professionals, since they are linked with business health, its lifespan and future perspective. Consequently, every economic unit in these circumstances would prefer to select the best possible employees. The process becomes more difficult when applications result non-successful due to lack of specific skills and experience. The fact that this problem appears to a considerable degreemakes us doubt the quality of educational degrees obtained by these applicants and if it is indeed so, how will the future of these individuals and companies be shaped? Whatever the answer on the root cause of the problem, it undoubtly remains challenging for all the above mentioned parties and moral duty directs us to examine possible solutions.

\section{Study Case: Vodafone Albania}

Vodafone Albania looks for the future leaders of their business in today's graduates, who have the ambition, drive and ideas to shape their own world. Discover Vodafone is the global graduate scheme which spans over 20 countries and is created to ensure the world's top graduates get the opportunity to join Vodafone.

By joining Discover Vodafone, graduates are empowered to help the company find the next big innovation for its customers. The Discover Program provides them with an accelerated career path. Gaining high business exposure from day one, they experience rotations in different areas of the organisation. It's a challenging and rewarding adventure, and as they work alongside some of the industry's leading experts they'll develop the solutions that will shape the customers' futures. And theirs.

The opportunities won't end there. If graduates show that they have the right capabilities and potential during the Discover Program, then they'll have the chance to experience Vodafone's truly global network through the Columbus Program. Taking on an international assignment, they'll gain the knowledge and insights that will prepare them for the next stage of their Vodafone career.

Over the course of 24 months, 15 of Albania's top graduates (selected from a pool of over 1000 aplicants), can expect to experience up to three different rotations - this will give them the chance to really get involved and make a name for themselves within their chosen field.

Their development pathway is a 'blended' learning strategy. Each Graduate will take responsibility for their own development - self managing through the two year program.

Each market will have an 'in country' business leader who sponsors the program. The top 15 graduates will have the opportunity to be leaded directly by the CEO of Vodafone Albania.

Their development will be delivered on the job through a series of 'real time' projects:

At least one project must be in a customer facing function : 
$\checkmark$ Sales or Customer Experience incorporating Retail;

$\checkmark$ Customer Contact Centre;

$\checkmark$ Business or Field Sales

Each project should be from a different discipline, i.e. each in a different function or department. Graduates should be assigned a line manager for the development year. This manager will act as a sponsor/coach for the graduate and should be a High Potential employee.

\section{How does Vodafone Differentiate and Entice the Best Young Talent to Join?}

The campaign needs to work in 20 markets across the world, with each able to develop additional executions reinforcing local market needs. It aims to attract and help filter 'Vodafone Fit' candidates; to build the talent pipeline and fill it with the best graduates from around the globe, increasing Vodafone's diversity and bringing in fresh thinking and perspectives.

The campaign is launched at the beginning of the academic year through presentations in the local universities, student organizations, online job boards, Vodafone global and local webpages.

The campaign communicates Vodafone's four brand pillars:

- Great People

- Global Player

- Innovative \& Dynamic

- World of Opportunities

The 'Vodafone Fit' graduate wants to do the things no one else has done. They want to lead from the front. They want to make decisions that have a real impact. They want to influence the lives of people across the world and shape their own future too.

\section{Internships}

Vodafone Albania Internship Program is very well designed to target undergraduate/masters students and MBAs with short previous work experience. It's an opportunity for them to explore the organization as well as develop themselves. It also aims to give to the company the opportunity to get to know them better by observing their performance and potential which they will reflect throughout their learning experience in Vodafone.

Vodafone builds its internship program based on 3 core principles:

1. They want their interns to gain outstanding experience and realise their potential while they are getting to know the organisation.

2. They want the interns to be their brand ambassadors and keep on attracting the best talent to Vodafone.

3. They see the interns as their future colleagues and therefore continue to invest in their talent pipeline.

In order to reach this goal Vodafone Albania was the first in the market to introduce Internship Agreements with the main universities in order to ensure that their top graduates were offered an internship from the company. The same was applied also with the main student organizations.

Furthermore, Vodafone Albania uses the network of former or current Discover Graduates to promote the program both locally and abroad.

It is this forward thinking and a very active participation on all events organized by universities, by offering free seminars, workshops or even open house days, that places Vodafone Albania as one of the most admired Employer Brands in the market. All this enables Vodafone Albania to select the best and invest on them ensuring not only a high retention rate and employee engagement, but also to have the right talent pool for it's future vacancies.

Perhaps a possible solution has been given by Susan Heathfield, who given the personal experience in Human Resources issues, makes several recommendations on recruitment to companies:

\subsection{Improve the candidates list (talent pool)}

- Dedicate time to develop relationships with university centers, recruiters and university research companies.

- Offer your current employees the possibility to actively participate in professional organizations and conferences where the will have the opportunity to meet the candidates you are trying to attract.

- Access online job seeking pages for potential candidates who may have posted there their references, even though they may not be currently looking for a job. Use professional web sites and magazines to announce 
vacancies requiring professional staff.

"The key is for organizations to create themselves a talent pool before they need it"(Heathfield, M, S. pg1)

\subsection{Hire the right employee.}

Bruce N. Pfau and Ira T. Kay, authors of "The Human Capital Edge", state firmly that organizations should hire an individual who has previously been in the right position in the right industry where there is the same business atmosphere and in a company with a very similar culture.

They believe that "past behaviour is the best predictor of future behaviour". Therefore, according to them, companies should hire candidates who can "nod" in the company, as it is of no value to expect to train candidates who may be succesful.

\subsection{Take into account current employees}

Ensuring promotion opportunities for current employees boosts their confidence and at the same time makes them feel appreciated.

At first, employers should concentrate on the current employees whenever they have vacancies. Another specific suggestion at this point is the usage of current employees in the process of selecting new employees, as no one knows the organization needs better than its current employees; whatsmore, since they will be part of the selection process, afterwards they will be committed to help the new employees.

\subsection{Be renowned as an excellent employer}

Post in your company website your vision, purpose, values, mission, achievements and products. It is necessary for you not only to become an excellent employer, but to also make this known to others. Try to present to the employees your practices on motivation, reporting, rewards, flexibility, work-life balance, promotion and integration. These are key areas in order to become employer of choice and if these benefits which you offer to the employees will be better than the industry median, then the results will be satisfactory.

However, we should not forget your skill to present to your employees the costs of these benefits because in this way they will appreciate your efforts for their wellbeing.

In the following example we are presenting the case of another mobile operator in Albania, which pays special attention to the human capital and its motivation. It states: "A safe, fair and friendly work environment is crucial for the performance and motivation of the employees, as well as their engagement. AMC is aware that when employees are engaged, performance is better and work satisfaction is higher. AMC holds a variety of activities where employees can participate, including those on voluntary basis."This case applies to the phase of managing and motivating employees who are now part of various companies. Emphasis is put on the importance of motivation and encouragement of staff with the purpose of improving its performance as "retaining the best employees after you have recruited them is easy if employers do the right thingswell." (Heathfield, M, S. Pg1).

\section{Conclusions}

At the first phase of an activity, after the business plan has been finalized and the activity starts being implemented, employees become its protagonists. To see how this business really works, we judge the quality of employees who have the potential to make the designed and set-up-in-advance structure functional, as well as totake the right decisions at the right time, an achievement which is measured through the financial results of the economic entity.

From the point of view of an entrepreneur the role his employees play is vital. Therefore, having good employees is important for any business because "human resourceslead to competitive atvantage when they are: valuable, rare, inimitable and irreplaceable"Barney (1991)

The analysis in this study begins with the description of the importance of human resources policies, how they should be, starting with the steps to be followed to recruit skilled and qualified people who will perform effectively and efficiently in their job.In this framework we mention the role of the Human Resources Department as responsible in matters related to employment, training, motivation and employee development within a company and we suggest alternatives on how to improve these policies. 
The part which we have considered highly important during this study is how to select the best employees. Specifically, it is suggested to put lots of effort in this phase by having the companies create their talent pool of selection, by exploring in universities, work associations, scientific conferences, or other alternatives such as the search of the best employees in the relevant industries, receive support from the current employees and provide a number of benefits for potential employees.

Another aspect, equally important, is that employers must make their employees happy, while the latter are motivated to perform at their best. It is important that business owners treat their employees as human beings, not as "robots", taking into consideration their ideas and suggestions and treat them with respect. The success of a company in recruiting the best employees depends mainly on the predisposition of the environment to encourage growth.

Finally, "human capital represents the human factor in an organization; the combination of intelligence, skills and expertise that gives the organization its distinctive character. The human elements of an organization are those that are capable oflearning, changing, innovating and providing the creative thrust which ifproperly motivated can ensure the long-term survival of the organization. Human capital can be regarded as the prime asset of an organization, andbusinesses need to invest in that asset to ensure their survival and growth.(Bontis, 1999).If the owners of an organization realize, appreciate and know how to make good use of the best values of each employee, there will come a day when the organization's success will not depend only on a positive balance sheet.

\section{References}

Agalliu A. (2013), "Human capital facing challenges of the bank system in Albania", pg 43.

Bank of Albania (2013), Annual Report.

Barney JB. (1991), "Journal of Management", pg 26-29.

Bruce N. Pfau, "The Human Capital Edge 21 People Management Practices Your Company Must Imlement or Maximise Shareholder Value", McGraw-Hill

Edwin A. Locke (2003), "Principles of Organizational Behavior".

Heathfield. M. S, "Top 10 Tips for Successful Employee Recruiting" fq1

Retreived from: http://www.humansecources.about.com/od/recruitingtips.htm

Optimum Resul, "Importance of Human Resource Management", Human Resource Excellence. Retrieved from: http://www. humanresourceexcellence.com/importance-of-human-resource-management/

Michael Armstrong (2008), "Strategic Human Resource Management", pg 19

R. A. Noe, J. R. Hollenbeck, B. Gerhart, P. M. Wright, (2011), pg 3.

R. Spitzer (2007). "Performance Measurement", pg 220.

http://www.infosoftgroup.com.al/human-resources/job-opportunities/human-resources/

http://www.amc.al/al/c/133/HR

http://www.flag-al.org/Flag AL_ORG_files/manuals/Modern\%20Human\%20Resource\%20Management.pdf

http://www.monitor.al/?p=8091

http://burime-njerezore.duapune.com/health/2011/shtator-2011/212-proceset-e-punes/1306-roli-i-burimeve-njerezore-ne-rritjen-efitimeve-te-bizneseve

http://www.gobookee.org/get_book.php?u=ahr0cdovl3d3dy5kb2t0b3jhdhvyys51bml0axiuzër1lmfsl3dëlënvbnrlbnqvdxbsb2fkcy8ymdezlza 210rva3rvcmf0dxjhlufyymktqëdhbgxpds1gyët1bhrldgktrëtvbm9taxnllurlcgfydgftzë50as1pluvrb25vbë|rc210Inbkzgplqvbjvefmssbivu1 btibqë4tsqkfmtmolifngsurbvkugvmolifnju1rftuluiejbtktbuiboë4sgli4u 